\title{
The Possibility of Cultural Cooperation Between China, Japan and South Korea and the Construction of East Asian Cultural Community
}

\author{
Jiayin $\mathrm{Liu}^{1, *}$ \\ ${ }^{1}$ Virginia Episcopal School- 400 V.E.S ROAD, Lynchburg, VA, 24503, US \\ *Corresponding author.Email: jliu@ves.org
}

\begin{abstract}
While the process of globalization continues, the common development of East Asian cultures becomes more important. The paper mainly focuses on the construction of the East Asian Cultural Community, especially about the cooperation between China, Japan and South Korea. This article firstly introduces the historical connections of the three countries to explain the basis of cooperation by mentioning the common religion and languages within them. Then, the article analyzes the obstacles and potential of the East Asian Cultural Community by referring to the existing benefits and drawbacks of cooperation, both economically and culturally. By explaining the theory of critical geopolitics, the article states that competitions in East Asia are intense in many fields, with the dramatic growing popularity of pop culture industries in Japan and South Korea weakening their will to share those unique parts of their cultures. However, economic benefits motivate the three countries to export their cultures, fostering the growth of catering while also advertising different customs in neighboring countries. With the convenience of social media and the spread of pop culture, the article agrees that successful cooperations above can encourage further construction of the East Asian Cultural Community. In conclusion, a larger scale of cooperation under development of the East Asian Cultural Community is accomplishable.
\end{abstract}

Keywords: East Asian Cultural Community, Critical Geopolitics, Cultural Exportation, The Cooperation Among China, Japan and South Korea.

\section{INTRODUCTION}

Even though the cultures of China, Japan and South Korea each have their own special colors since the beginning of their history, from an international perspective, they still have great unity. Accompanying globalization and the development of the Internet, other regions of the world are becoming more interested in East Asian culture, reflecting its potential beneficial of popularizing East Asian countries. Since 1989, the AsiaPacific Economic Cooperation has promoted the economic ties of East Asian countries, later establishing a strategic partnership in 2008. However, cultural cooperation has been delayed for years. Behind this situation is the fierce competition among East Asian countries and their guard against each other under geographical connections. How to find a way of cooperation is becoming a common research question in East Asia. Therefore, this article will be divided into three parts, mainly analyzing the foundation of the East Asian
Cultural on the basis of history, while using critical geopolitics to explain the political competition between countries and the future development prospects. The research of this paper is helpful to understand the viability of breaking the deadlock in East Asia and anticipate the potential of cultural industries.

\section{ANALYSIS OF THE FOUNDATION OF EAST ASIAN CULTURE}

The historical connections between China, Japan and South Korea began as early as the Han Dynasty in China (2nd century BCE), and until modern times, well-known cultural exchanges include the ambassadors sent by Japan to the Tang Dynasty (around 8th century BCE). Geographical factors have caused East Asia to become an independent region since ancient times. Not only Western merchants, but the spread of Western culture also needed to pass a fixed route formed by East Asian countries. For example, Buddhism originated in India, spread to China 
through Central Asia, and later went across the sea to Japan and South Korea. Different from religious practices in India, Zen Buddhism is a new form of Buddhism created in China, advocating self-cultivation and thoughtfulness about principles of the world. In Japan, Zen combines with the local culture to highlight the "peace" part, which significantly impacted East Asian cultures. For example, in Korea, the

Order of Zen is still the largest branch of Buddhism. Though Zen Buddhism was introduced to Southeast Asia, its influence was limited. The shared thoughts like Buddhism and Zen provided basis for communication between three East Asian countries. East Asian culture thus has a religious and philosophical agreement, and there is room for enhanced exchanges.

Another important example of East Asian cultural interaction is language. Both Japanese and Korean borrowed Chinese characters, and once constructed a "culture circle of Chinese characters". However, in modern days, after Japan and South Korea opened their doors to Western countries, the part of the language that they had borrowed went back to China. For example, the Japanese translation of "democracy" was adopted by the Chinese in the early twentieth century, reflecting the frequent exchanges between the three countries. Language produces literature, and the aesthetic symbols in East Asian literature are also very similar. Sijo in South Korea, Haiku in Japan and traditional Chinese poetry often appear in bamboo forests, courtyards, and moons. These symbols rarely appear in Western literature and are special traces of East Asian culture.

With such similar cultures, China, Japan and South Korea have already had a deep understanding that can be used as a basis for cooperation.

\section{EXISTING PROBLEMS}

In most cases, geopolitics does not represent friendship, but embodies the discourse power relationship[1]. For example, the main goal of EU countries is to seek their own interests, so that conflicts often occur among them. In the process of globalization, the goal of every country is to increase its voice on the international stage, whether it is military, political, or cultural. Under such circumstances, critical geopolitics has emerged in order to more clearly interpret the competition motives of countries in the region. Two of its research themes are: geopolitical traditions and popular culture[2].

Though having similar cultures, China, Japan and South Korea have rarely cooperated in this area at the national level. From the Japanese invasion of South Korea in the 18th century to World War II, and now the confrontation between Japan and South Korea and China, the main purpose of the three countries is to stand out and become regional leaders and participate in international affairs. Affected by world politics in the 20th century, in the Far East, the main political and economic patterns have been settled. Due to geographical factors, these three countries still maintain close trade relations - in 2012, the trade volume between China and Japan and South Korea reached 585.7 billion U.S. dollars, which together accounted for $15.1 \%$ of China's total foreign trade imports and exports[3]. However, with such a huge volume, economic benefits of constructing a cultural community cannot account for a considerable percentage that weighs over the idea of keeping the uniqueness of cultures to the country itself. Therefore, it is difficult for the three countries to take initiative to challenge this field.

Table 1 Cultural Trade Surplus of East Asian Countries (\$ million)

\begin{tabular}{|l|l|l|l|}
\hline & 2010 & 2011 & 2012 \\
\hline China & -247.9 & -276.8 & -438.9 \\
\hline Japan & -645.3 & -713.7 & \\
\hline $\begin{array}{l}\text { South } \\
\text { Korea }\end{array}$ & -171.5 & -58.4 & 1.9 \\
\hline
\end{tabular}

Just as the English-dominated Western society has a relatively unified hip-hop and rock culture, China, Japan and South Korea also have similar pop cultures. Among them, the most widely spread are Japanese animation and Korean pop music (K-POP). In June 2021, the Ministry of Culture, Sports and Tourism of Korea issued the "Analysis Report on the Trends of the Cultural Industry in 2020". In 2020, the export volume of South Korea's cultural content industry will be 10.83 billion U.S. dollars[4]. The growth of Japanese animation is also fast, with its industrial value in 2016 increasing by 210 billion yen year on year.[5] 


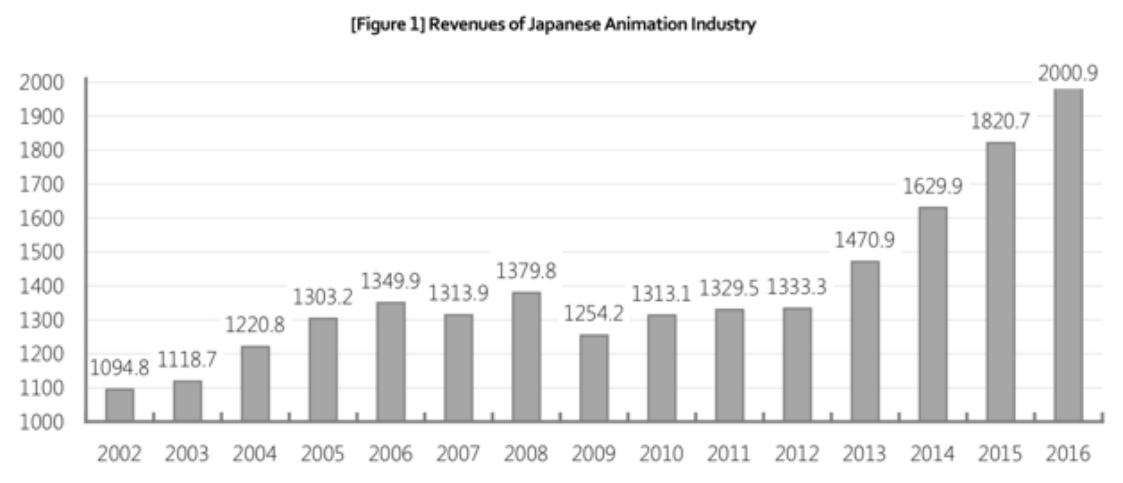

Figure 1. Revenues of Janpanese Animation Industry

However, thinking of the geopolitical theory, there are competitive motives behind these national actions. The benefits of popular culture exports are reflected in cultural assimilation. The interests of the younger generation make these popular cultures a unique business card of the country. Throughout the 20th century, American power is not only embodied in politics, but international dominance has also led to American popular culture, such as hip-hop, spreading all over the world, achieving the dramatic growth of soft power. Nowadays, if East Asia wants to catch up with the United States, support for cultural exports is indispensable. In this case, cooperation means integration. In modern geopolitics, the market interests of national territories have replaced geopolitical logic[6], which means that China, Japan and South Korea still need to compete for the market of pop cultures, making it difficult for them to accept the loss of unique characteristics. It also caused significant obstacles to the advancement of the East Asian Cultural Community.

\section{COOPERATION PROSPECT}

\subsection{Based on traditional culture}

Compared with the various popular cultures of different countries, traditional cultures have achieved integration and mutual learning in East Asia. This sharing of cultures has fully prepared for harmonious development for cultures of the three countries. The world's first Confucius Institute was established in South Korea in 2014, which is inseparable from the cooperation of both governments. Japanese and Korean culture is deeply influenced by Confucianism. In addition to the disciplinary power of the family, there is also the concept of "friends" in Confucianism-it is believed that among friends, the most important thing is to have the same goal and the opportunity to learn from each other. This is exactly the same with the relationship between East
Asian countries: even if there are difficulties, the ultimate expectation of the three sides is still peaceful cooperation, and the historical foundation also provides chances for communications. In the "Japan's Cultural Policy" issued by the Agency for Cultural Affairs in 2011, it was clearly stated: "Strengthening relations with the East Asian countries headed by China, South Korea, and ASEAN countries has become an issue for the entire country. Cultural exchanges that contribute to mutual understanding at the national level have become a topic"[7]. In the 21 st century, the three countries have established Confucianism, Buddhism, and traditional art forums, which all represent that governments have started to pay more attention to cultural integration and influence.

\subsection{Based on new media and popular culture}

Since the late 20th century, China has established diplomatic relations with Asian countries one after another. Due to the communications between countries, in the past few decades, the younger generation has been influenced by foreign cultures, and their understanding of the "state" is often more open, more willing to break down barriers and accept new things. First of all, with the Internet as a medium, the proliferation of new media provides the conditions for the spread of culture. Foreign TV programs can now be watched on websites, and you can also upload your own videos freely, such as "VLOG" for recording daily life and "Mukbang" for filming food. In this way, the food and customs of countries can be better understood. The 2021 China Catering Industry Annual Report shows that although there has been a decline, Japanese products still occupy $5 \%$ of the market, while Korean products account for about 3\%[8]. After the impact of the COVID-19 epidemic has passed and the economy has rebounded, these catering industries will bring economic benefits. In areas that are heavily influenced by foreign cultures, such as Northeast China 
where Koreans tend to live, if cultural cooperation areas can be advertised on the Internet, the advantages of short geographic distance can also be used to promote tourism. Secondly, in terms of popular culture, in addition to the pop music introduced above, which has national capital support, there are also multinational investments in the game and film and television industries. Globalization cannot eliminate the aesthetic differences between the East and the West, so themes of movies and games are usually more acceptable in the East Asian region, which has similar cultures. This easier way of success attracts more East Asian companies to invest in their neighbors. Therefore, the support of media and pop culture can promote cultures of the three countries to a better future.

\section{CONCLUSION}

This paper has done research on the basis, difficulties and future of the East Asian Cultural Community. For these topics, the article draws the conclusion that communications between China, Japan and East Asia that lasted for a thousand years are the solid basis for the Cultural Community. However, to achieve economically and culturally win-win, the three countries must overcome the inevitable competitions caused by their close geographic distance. Also, it is better for them to borrow the advantages of pop culture and social media to increase the influence of their own culture in neighboring countries. The popularity of Japanese and Korean pop cultures proves the viability of the cultural exportation; besides, the three countries can seek the most exploited of the shared cultures, like putting expectations in the film production, using the common themes to gain acceptance of people in other countries. However, one thing that this research paper has not mentioned is politics To improve, future studies shall add political factors, to make the analysis of the East Asian Cultural Community more comprehensive.

\section{ACKNOWLEDGMENTS}

The most thanks should be given to my tutor, who guides me and provides suggestions on how to polish this paper. Also, without the foundation of previous researchers, I will not be able to support the paper with strong evidence, great thanks to them. At last, thank my mother for always encouraging me to learn things that I'm truly interested in, I could not have got here without her.

\section{REFERENCES}

[1] Sun Xiangdong. Geopolitics: The perspective of postmodernism criticizes. Journal of University of International Relations, 2006(1): 44-49.

[2] Dodds K. Political geography III: Critical geopolitics after ten year. Progress in Human Geography, 2001, 25(3): 469- 484.
[3] Mao Hanying. Geopolitical and geoeconomic situation in the surrounding areas and China's strategies. Progress in Geography, 2014, 33(3): 289302.

[4] Sports and Tourism of Korea. Analysis Report on the Trends of the Cultural Industry in 2020, 2021.

[5] Japan Animation Association. Animation Industry Report 2017, 2018.

[6] Sami Moisio, Anssi Passi. From geopolitical to geoeconomic. The changing political rationalities of state space[J]. Geopolitics, 2013, 18(2): 267-283.

[7] Tang Yongliang. An Analysis of the Thought of East Asian Cultural Community in Japan. Journal of Yanbian University(Social Science), 2013, 46(1): 42-48.

[8] Xinhua Net. The 2021 China Catering Industry Annual Report, 2021-8-23 